\title{
Evaluation of Microstructures of ZnO Nanocrystals Fabricated by Different Methods
}

\author{
A.Y. ORAL \\ Dept. of Materials Science and Engineering, Gebze Institute of Technology, 41400, Kocaeli, Turkey
}

\begin{abstract}
$\mathrm{ZnO}$ nanocrystalline powders were fabricated by the solutions prepared by dissolving zinc acetate in isopropyl alcohol. Ethanolamine was used to enhance the solubility of acetates. Nanocrystalline powders were obtained either from the dried gels or precipitated solutions followed by calcination at different temperatures. Microstructural characterization of the powders showed that both morphology and the crystallite size of powders significantly altered based on the fabrication method and the calcination temperature.
\end{abstract}

DOI: 10.12693/APhysPolA.123.169

PACS: 81.07.Wx

\section{Introduction}

$\mathrm{ZnO}$ powders have been widely used since the end of 18 th century, mostly as a white pigment [1]. Zinc oxide nanocrystalline powders have been extensively studied in the past years because of their promising physical and chemical properties, which could lead to a wide range of applications such as varistors, piezoelectric devices, surface acoustic wave devices, chemical sensors and other areas using their antibacterial activity [2]. Recently, nanostructured zinc oxide is also considered to be used as a fluorescent powder for fingerprint detection [1].

Various methods have been employed to produce $\mathrm{ZnO}$ nanopowders, such as, ultrasonic spray pyrolysis [3], controlled microwave-assisted synthesis [4], hydrothermal synthesis [5], sol-gel direct precipitation [6], and gel drying followed by thermal decomposition [7]. Among methods for materials synthesis, sol-gel method is of great interest because it is a relatively inexpensive processing that can be applied to wide range of materials. In addition, sol-gel process has a potential advantage over most of the other methods for accomplishing homogeneous mixing of the components on the atomic scale [2].

In present work, we report on the microstructure of sol-gel derived nanocrystalline powders prepared with different process parameters. There have been many studies on sol-gel derived $\mathrm{ZnO}$ nanopowders. However, variations of their microstructure by different process parameters have been less frequently studied.

\section{Experimental}

Schematic of experimental procedure was given in Fig. 1. The solutions were prepared by dissolving zinc acetate $\left(\mathrm{Zn}\left(\mathrm{CH}_{3} \mathrm{COO}\right)_{2} \cdot 2 \mathrm{H}_{2} \mathrm{O}\right)$ in isopropanol $\left(\mathrm{CH}_{3} \mathrm{CHOHCH}_{3}\right)$ and ethanolamine $\left(\mathrm{C}_{2} \mathrm{H}_{7} \mathrm{NO}\right)$. After that the solutions were stirred for $20 \mathrm{~min}$ by using a magnetic stirrer for homogeneous mixing. The final solutions, with concentrations of $4 \mathrm{M}$, were light brown and clear without any suspension of particles. For nanoparticle fabrication via gel dying, the solution was dried under open atmosphere for one week. Afterwards, the dried gels were calcinated at $750^{\circ} \mathrm{C}$ for $2 \mathrm{~h}$. Resulting powders were passed through a $30 \mu \mathrm{m}$ sieve to separate agglomerated particles during calcination. During nanoparticle fabrication via precipitation route, $\mathrm{pH}$ of the sol was increased from around 6 to 12 by adding $\mathrm{KOH}$ solution to final solution. The precipitates were filtered and calcinated at temperatures between $200-400{ }^{\circ} \mathrm{C}$ for $2 \mathrm{~h}$. The surface morphologies of the powders were examined by scanning electron microscope (SEM — Philips XL 30 SFEG).

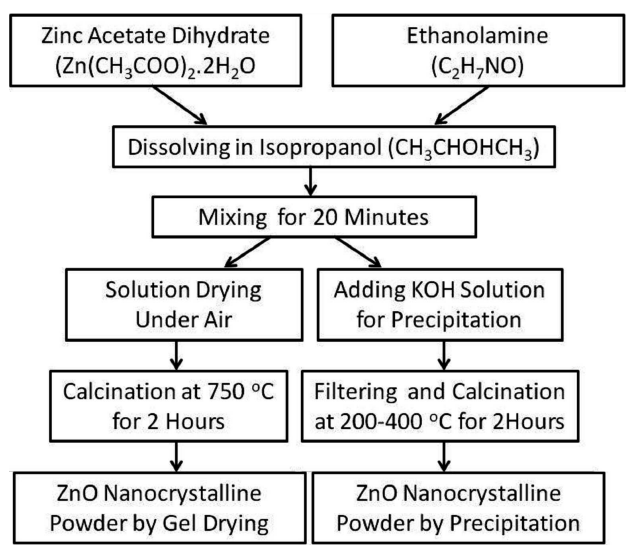

Fig. 1. Schematic of experimental procedure.

\section{Results and discussion}

SEM micrographs of the powders showed that both morphology and the crystallite size of powders significantly changed based on the fabrication method and the calcination temperature (Figs. 2 and 3). Low magnification SEM micrographs showed that agglomeration was minimal in powders after the calcinations at $200{ }^{\circ} \mathrm{C}$ and size of the particles varied between $500 \mathrm{~nm}$ to $10 \mu \mathrm{m}$ (Fig. 2a). The powders calcinated at $300^{\circ} \mathrm{C}$ had moderate agglomeration after the calcination and the size of the particles varied between 2 to $20 \mu \mathrm{m}$ (Fig. 2b). The powders calcinated at $400^{\circ} \mathrm{C}$ had extensive agglomeration. 


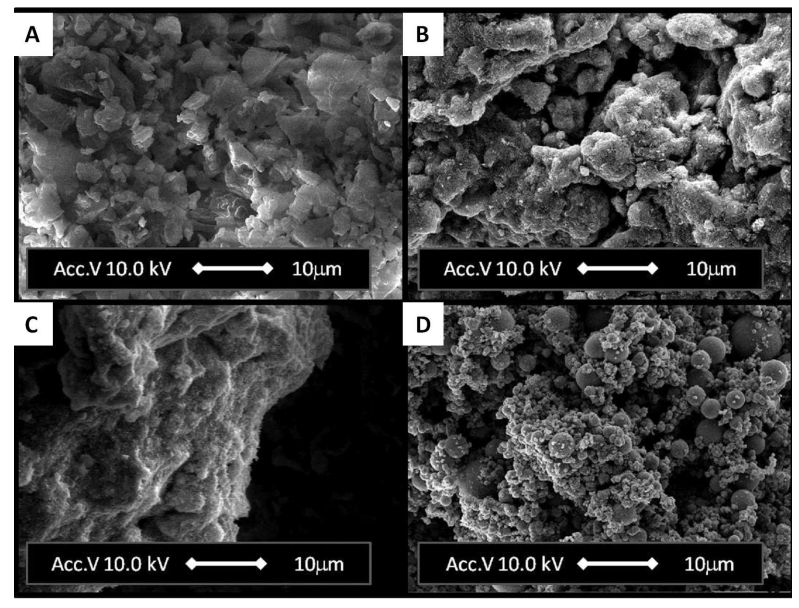

Fig. 2. Low magnification SEM micrographs: (a) precipitated and calcinated at $200{ }^{\circ} \mathrm{C}$, (b) precipitated and calcinated at $300{ }^{\circ} \mathrm{C}$, (c) Precipitated and calcinated at $400{ }^{\circ} \mathrm{C}$, (d) gel dried and calcinated at $700{ }^{\circ} \mathrm{C}$.

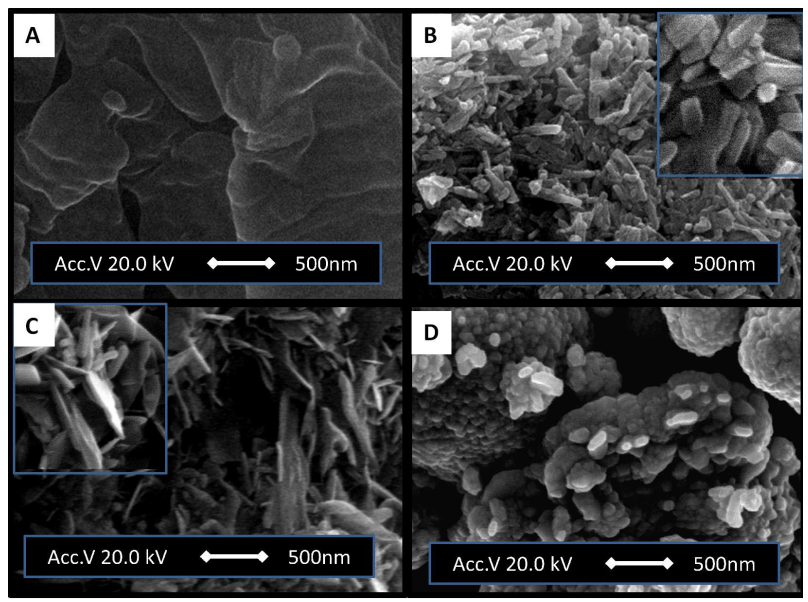

Fig. 3. High magnification SEM micrographs: (a) precipitated and calcinated at $200{ }^{\circ} \mathrm{C}$, (b) precipitated and calcinated at $300^{\circ} \mathrm{C}$, (c) precipitated and calcinated at $400{ }^{\circ} \mathrm{C}$, (d) gel dried and calcinated at $700^{\circ} \mathrm{C}$.

The particles looked like sintered to form porous ceramic crumbles (Fig. 2c). SEM micrograph of the powders ob- tained after calcination of dried gels at $700{ }^{\circ} \mathrm{C}$ showed spherical particles sized between $500 \mathrm{~nm}$ to $10 \mu \mathrm{m}$ in diameter. They are most likely formed by the aggregation of nanosize crystallites (colloids) preexisting in the sol (Fig. 2d).

High magnification SEM micrographs showed that the powders calcinated at $200^{\circ} \mathrm{C}$ did not fully crystallize (Fig. 3a). The powders calcinated at $300^{\circ} \mathrm{C}$ showed anisotropic grain growth to form nanorods with a few hundred nanometer lengths. Their width changed in the range $50-80 \mathrm{~nm}$ (Fig. $3 \mathrm{~b}$ ). The powders calcinated at $400^{\circ} \mathrm{C}$ had mixed morphology made up of needles and flakes which have lengths varied between a few hundred nanometers to a few $\mu \mathrm{m}$ (Fig. 3c). The shape of crystals formed by calcination of dried gels was spherical with diameters around $50 \mathrm{~nm}$ (Fig. 3d).

\section{Conclusion}

Morphology and the crystallite size of pure $\mathrm{ZnO}$ powders significantly altered based on the fabrication method and the calcination temperature. Gel dried crystals were smaller and have higher isotropy than precipitated crystals. The anisotropy of the crystals fabricated by solution precipitation method increased with the calcination temperature.

\section{References}

[1] M.J. Choi, K.E. McBean, P. Hei, R. Ng, A.M. McDonagh, P.J. Maynard, C. Lennard, C. Roux, J. Mater. Sci. 43, 732 (2008)

[2] L. Znaidi, Mater. Sci. Eng. B 174, 18 (2010).

[3] P. Singh, A. Kumar, D. Deepak, Kaur, J. Cryst. Growth 306, 303 (2007)

[4] Y. Liu, Y. Hu, M. Zhou, H. Qian, X. Hu, Appl. Catal. B, Environmental 125, 425 (2010).

[5] Y. Wang, J. Sun, X. Fan, X. Yu, Ceram. Int. 37, 3431 (2011)

[6] C.C. Chen, P. Liu, C.H. Lu, Chem. Eng. J. 144, 509 (2008).

[7] S. Rani, P. Suri, P.K. Shishodia, R.M. Mehra, Solar Energy Mater. Solar Cells 92, 1639 (2008) 